\title{
A influência do Estado e do mercado na administração da cultura no Brasil entre 1920 e 2002*
}

\author{
Janaina Machado Simões** \\ Marcelo Milano Falcão Vieira***
}

SumáRIo: 1. Introdução; 2 . A cultura como um campo organizacional; 3. Metodologia; 4. Evolução do setor cultural brasileiro; 5. A influência do Estado e do mercado no campo organizacional da cultura; 6. Conclusões.

Summary: 1 . Introduction; 2. Culture as an organizational field; 3. Methodology; 4. Evolution of the Brazilian cultural sector; 5 . The influence of the state and of the market in culture's organizational field; 6 . Conclusions.

Palavras-chave: cultura; indústria cultural; campo organizacional; Estado; mercado.

KEY WORDs: culture; cultural industry; organizational field; State; market.

Grande parte das discussões do setor cultural no Brasil apresenta, genericamente, dois focos principais. O primeiro diz respeito ao debate de quem seria o responsável pela cultura, se o Estado ou o mercado. Já o segundo, trata do desenvolvimento de uma indústria da cultura e suas consequentes preocupações estratégicas e mercadológicas. A partir de uma abordagem metodológica qualitativa, este artigo analisa as influências do Estado e do mercado nas transformações ocorridas no campo organizacional da cultura no Brasil no período entre 1920 e 2002. Os resultados obtidos permitiram verificar que quanto mais intensa for a presença do Estado no campo, maiores serão a complexidade e o grau de institucionalização dele. Já em relação

\footnotetext{
* Artigo recebido em mar. e aceito em nov. 2009.

** Professora da Universidade Federal Rural do Rio de Janeiro. Mestre em administração pública pela Escola Brasileira de Administração Pública e de Empresas (Ebape) da Fundação Getulio Vargas (FGV). Coordenadora do Grupo de Estudos em Administração Contemporânea. Endereço: Praia de Botafogo, 190 - 5o andar - CEP 22250-900 — Rio de Janeiro, RJ, Brasil. E-mail: janaina. simoes@fgv.br.

**** Professor da Ebape/FGV. PhD em administração pela University of Edinburgh. Coordenador do Grupo de Pesquisa Observatório da Realidade Organizacional. Endereço: Praia de Botafogo, 190 - 5o andar — CEP 22250-900 — Rio de Janeiro, RJ, Brasil. E-mail: marcelo.vieira@fgv.br.
} 
ao mercado, quanto mais presente este se faz no campo, mais os atores parecem ter dificuldades em obter sua legitimação no ambiente. Dessa forma, nem a ação do Estado nem a ação do mercado foram suficientemente fortes para promover mudanças significativas na lógica que orienta a configuração organizacional do campo. As transformações nas configurações do campo organizacional da cultura acontecem somente quando a lógica determinada pela dinâmica histórico-social do ambiente do qual o campo faz parte se modifica.

The influence of the state and of the market in the management of the cultural field in Brazil between 1920 and 2002

Generally speaking, great part of the debate in the cultural sector in Brazil has two main focuses. The first one refers to who is responsible for structuring the field: the State or the market. The second deals with the development of a cultural industry as well as its strategic and marketing propositions. This article adopts a qualitative approach to analyze the influences of the State and of the market on the changes occurred in culture's organizational field between 1920 and 2002. The results show that the more intense is the presence the State in the field, higher is its complexity and its degree of institutionalization. On the other hand, the more the market is present in the field, the more social actors have difficulty in legitimating themselves. Nevertheless, neither the State nor the market are enough to promote significant changes in the logic that guides the configuration of the cultural field in Brazil, which depends on the dynamics of social-historical elements.

\section{Introdução}

Vários estudos têm mostrado que as organizações culturais vêm adotando práticas que satisfaçam às exigências do ambiente técnico ao qual pertencem, porém tal compreensão seria incompleta ou restrita para um claro entendimento do complexo campo das organizações culturais no Brasil. Isso porque muitas organizações adotam estruturas, regras, normas e valores que não respondem apenas a uma lógica de eficiência, mas também a uma lógica institucional, na qual são adotados símbolos, valores, ritos e ações cerimoniais - socialmente construídos —, visando à legitimação e ao reconhecimento social.

Outro ponto importante é que parece, de certa forma, ser marginalizada a discussão em relação às consequências a que, em longo prazo, as organizações culturais estariam expostas com o desenvolvimento de uma indústria cultural e com a predominância de uma lógica mercadológica e gerencial. É fundamental que algumas implicações dessa perspectiva sejam questionadas, não realizando juízos de valor simplificado, e sim analisando criticamente o papel que a cultura passaria a assumir, a que interesses passaria a servir e, 
acima de tudo, se o desenvolvimento de suas organizações representativas não estaria apenas reproduzindo e consolidando processos de manipulação e alienação presentes na sociedade.

Vários estudos já realizados no Brasil a respeito da incorporação de uma lógica mercantil pela cultura (Carvalho e Vieira, 2003) apresentam comprovações empíricas - com base na teoria institucional e de campos organizacionais - de que a base originalmente lúdica da cultura estaria gradualmente dando lugar a uma base instrumental, orientando assim as ações das organizações culturais. Tais estudos têm indicado a centralidade do papel do Estado no processo de mercantilização da cultura e também que a busca por um equilíbrio entre os ambientes técnico e institucional vêm representando ponto fundamental para a sobrevivência organizacional. O desenvolvimento desses estudos permitiu grandes avanços na compreensão do papel da cultura no contexto brasileiro e, ao mesmo tempo, trouxe à tona questões que necessitam ser repensadas tanto no plano teórico quanto no plano empírico.

Outro aspecto que merece destaque diz respeito à relação entre a perspectiva teórica utilizada nas pesquisas sobre o campo das organizações culturais. A utilização da abordagem institucional contribuiu bastante para compreender as questões que tratam da cultura em um contexto em que a complexidade de relações e a subjetividade das ações organizacionais parecem ser uma característica determinante. Além disso, o conceito de campos organizacionais vem se mostrando uma grande ferramenta teórica para compreensão da relação das organizações culturais com outros atores que fazem parte de seu ambiente. Mesmo assim, essa perspectiva teórica vem apresentando algumas limitações como: a dificuldade diante do contexto brasileiro de se estabelecerem critérios de análise consistentes para a definição de algum limite entre os ambientes técnico e institucional, uma vez que o próprio conceito de eficiência parece estar institucionalizado; no momento em que o papel do público - ou cliente - da cultura é deixado em segundo plano nas análises, mesmo por opções metodológicas, parece estar se desconsiderando que esse ator possa ser um dos principais.

Ao refletir-se a respeito da atual situação da cultura no Brasil parecer ser evidente que esta - considerando-se os diversos problemas sociais e econômicos do país - não foi a pauta central nem da sociedade nem do mercado, tampouco foi uma prioridade governamental ao longo do tempo. Logicamente, não se ignora o interesse do mercado em certos "produtos" culturais, nem o protesto de alguns grupos pelo sucateamento do aparelho estatal cultural e muito menos o fato de algumas políticas públicas utilizarem a cultura como ferramenta de inclusão social. Mas o que é fundamental 
de ser destacado é que o papel secundário que o campo da cultura possui atualmente não é um fenômeno recente, mas um processo construído historicamente pela própria sociedade e que sofreu influências do Estado e do mercado ao longo do tempo.

Diante dessa problemática, este artigo analisa qual a influência do Estado e do mercado nas transformações ocorridas no campo organizacional da cultura no Brasil no período entre 1920 e 2002. O recorte temporal analisado parte de 1920, pois os eventos e as organizações anteriores a esse período são considerados incidentes que teriam originado o campo. Assim, este passa a ser descrito como tal apenas a partir da década de 1920, com a sistematização de eventos e com criações continuadas de organizações. Posteriormente, a data de término da análise, 2002, diz respeito ao último período governamental brasileiro completo até o término da pesquisa que originou este artigo.

Para a realização deste artigo partiu-se da perspectiva de campos organizacionais (DiMaggio e Powell, 1991; Meyer e Rowan, 1991; Scott, 1994; Vieira, Carvalho e Silva, 2009) como ferramenta teórica para a construção das análises da evolução do setor cultural no Brasil. Buscou-se realizar uma análise teórico-empírica, contrapondo os resultados encontrados ao longo da análises dos dados aos argumentos teóricos dos principais autores que discutem a temática proposta.

\section{A cultura como um campo organizacional}

A cultura — segundo Ianni (2004) —, apesar de apresentar especificidades como sistemas significativos, construções ideais e conjuntos que articulam o passado e o presente, cria-se e recria-se por meio das relações sociais. A cultura, para o autor, possui vida própria, assim como a sociedade e os diversos grupos que a compõem. Ianni (2004), porém, afirma que a cultura não é inocente, e uma vez que suas expressões culturais são criadas e recriadas no jogo das relações, os antagonismos e as diversidades sociais, políticos e econômicos, também estão presentes nelas. Esses antagonismos sociais, segundo ele, constituem a sociedade e manifestam-se na cultura por meio de imagens, metáforas, significados, símbolos e outros elementos.

A organização institucional da cultura muda, segundo Marques (1995), com maior ou menor significado, de país para país, refletindo não só as diferentes contradições administrativas como também diferentes realidades no que diz respeito ao papel do Estado e à autonomia e participação da sociedade civil. Na área cultural, para Durand (2001), há uma pluralidade de interesses 
ativos: grupos, associações, revistas, fontes de financiamento, identidades e qualificações intelectuais, técnicas, estéticas, políticas e administrativas, com diversos interesses e pontos de vista que se confrontam em espaços sociais relativamente independentes entre si.

As organizações culturais, em sua maioria, são reguladas pelo Estado e dependem de financiamento para desenvolver suas atividades. Ao mesmo tempo, precisam obter a legitimidade de suas ações para garantir sua sobrevivência. A busca pela legitimidade social vem fazendo tais organizações abandonarem suas antigas estruturas e processos de gestão e incorporarem modelos gerenciais tipicamente privados, como afirmam Goulart, Menezes e Gonçalves (2003). Análises semelhantes podem ser encontradas em estudos como o de Vieira e Carvalho (2003), que analisam comparativamente a estruturação do campo das organizações culturais de Porto Alegre e Recife, tendo por base a noção de campos da teoria institucional.

Os estudos de Goulart, Menezes e Gonçalves (2003) inferem que a sobrevivência de uma organização cultural dependerá da manutenção e de um permanente ajuste entre as pressões de legitimidade, impostas pelo seu ambiente institucional por meio de normas e costumes socialmente aceitos, e das exigências do ambiente técnico pela eficiência e eficácia. A falta de harmonia nesse ajuste poderá acarretar relações conflituosas entre eficiência e legitimidade.

Parece ser importante e, ao mesmo tempo, complexa a importância da trajetória histórica, social, econômica e política, na alteração ou manutenção do sistema de valores do campo. Até onde vai a força do ambiente na configuração do campo? Será que as próprias organizações que o compõem não seriam capazes de impor mudanças ao ambiente? A própria importância simbólica do campo poderia ser um fator preocupante nessa análise, já que a busca pela eficiência dita a dinâmica do campo, logo sua importância simbólica estaria restringida no momento em que se deixam de lado os valores culturais e priorizam-se os valores do mercado.

Goulart, Menezes e Gonçalves (2003) analisam o campo organizacional dos museus e teatros de Recife diante das mudanças ocorridas no ambiente institucional do qual ele faz parte, tendo por base a teoria institucional. Os autores apontam que a origem das pressões sofridas pelo campo e o processo de obtenção de legitimidade variam, não havendo dicotomia entre o ambiente técnico e o institucional. Salientam também a forte influência do Estado na regulação e no financiamento das instituições e a incorporação da lógica gerencial privada para o alcance da legitimidade social. Os autores destacam que a sobrevivência da organização dependerá do ajuste entre as pressões de 
legitimidade oriundas dos ambientes técnico e institucional e a influência do contexto de referência no campo.

Talvez o ponto mais discutível seja como atender aos requisitos do ambiente técnico e do ambiente institucional. Será que a sobrevivência da organização depende do ajuste entre as lógicas ou será que a lógica de mercado já não estaria sendo institucionalizada no campo da cultura? Parece que estaria cada vez mais difícil definir objetivamente o que as organizações culturais entendem e praticam por eficiência.

Vieira e Leão Jr. (2000) narram o processo de institucionalização e mudança no Museu de Arte Moderna de Recife tendo por base a não existência de uma metanarrativa explicativa de fatos sociais e organizacionais e a interferência do poder no processo de institucionalização e geração de mudanças nas organizações. Os autores apontam que houve um confronto entre os conjuntos de valores já existentes e os trazidos por novos componentes, que resultou em mudanças na direção do museu. Assim, o "jogo" de poder, isto é, as interações entre os diferentes atores que compunham o cenário ou ambiente da organização, acabaram por ser fundamentais na dinâmica das organizações.

Com a utilização da perspectiva do poder como base para a análise da dinâmica de institucionalização de uma organização cultural, parece que a existência do conflito de interesses pode ser uma das origens da mudança institucional. Porém, outros fatores podem também proporcionar tal transformação, principalmente os oriundos do próprio ambiente institucional no qual o museu está inserido. Quando se fala em poder, parece estar se priorizando uma dimensão individualizada das relações, pois se o poder sempre estará presente, talvez fatores como a existência de valores e outras pressões externas influenciariam o rumo que os atores tomam.

O papel do Estado também vem sendo significativo no desenvolvimento dos campos organizacionais da cultura, seja por meio do poder coercitivo que exerce, seja por meio da dependência de financiamento e legislações de incentivo que proporciona. Pode-se questionar ainda se não seria o Estado o responsável original pela incorporação da lógica gerencialista e de mercado pelo campo da cultura, uma vez que o próprio Estado incorporou tal lógica e vem atribuindo ao mercado um papel que originalmente era seu.

A dificuldade em estabelecer os limites do campo da cultura parece evidente, já que há configurações estaduais, locais ou federais podendo ser estabelecidas de diferentes maneiras, de acordo com a área da cultura priorizada. Além disso, o papel do pesquisador parece estar à prova, pois além de precisar deixar cada vez mais claras suas opções teóricas, necessita estabelecer con- 
versações entre teorias e metodologias de estudo que consigam contornar as limitações por elas apresentadas.

Carvalho, Pacheco e Guimarães (2004) apresentam uma reavaliação de artigos que tratam do campo da cultura e têm por base a teoria institucional e a de campos organizacionais. Os autores apontam que todos os textos possuem como elo comum o papel do Estado e das políticas públicas como determinantes das mudanças ocorridas nas ações das organizações. O Estado assume, em diferentes contextos, papéis de dinamizador, preservador, fomentador, transformador, legislador e controlador e, mesmo com a transformação que o Estado sofreu mediante a reforma gerencial, seu papel de interventor permanece. Por fim, eles concluem que o Estado tem se movimentado em direção ao fomento de uma autossustentação das organizações culturais.

Porém ainda existem lacunas em relação a um entendimento mais profundo sobre o papel do Estado. Um ponto questionável diz respeito às contradições dos autores quando comentam a respeito da isenção fiscal, já que ao mesmo tempo em que estabelece que a cultura nunca foi foco do Estado, argumenta-se que a isenção fiscal é realizada para setores estratégicos. Outro ponto duvidoso é que os autores afirmam que o Estado estaria se movimentando para a autossustentabilidade das organizações culturais, porém, questionase se apenas não estaria em transição de uma dependência estatal para uma dependência privada. Assim, diversas questões em relação à cultura brasileira não foram ainda respondidas, principalmente quanto ao papel que a cultura desempenhou ao longo do tempo e quanto à lógica que predomina em suas manifestações ou gestão. Verifica-se que o campo organizacional da cultura no Brasil apresenta uma série de contradições, fruto de sua evolução histórica e de suas relações com atores do Estado e do mercado que precisam ser melhor analisadas.

\section{Metodologia}

Este artigo tem como foco os atores organizacionais que compõem o campo da cultura. A análise feita para este artigo ficou centrada em uma visão geral do campo da cultura, sem detalhar especificamente as relações entre as diferentes manifestações culturais. O nível da análise foi o campo, já que foi visto o conjunto das organizações da cultura como um todo, e as unidades de análise são os atores que compõem e caracterizam o campo (Vieira, 2004). Tais atores são de origem privada, da sociedade civil ou, ainda, pública. 
A pesquisa foi composta por três fases. A primeira, bibliográfica, tratou da análise histórica do campo organizacional da cultura. A segunda, bibliográfica e documental, é a análise das diferentes configurações do campo ao longo do tempo. Na última, interpretativa, se estabeleceu uma comparação entre as diferentes configurações e sua relação com o Estado e o mercado. Ao final dessas etapas, foram identificadas quatro configurações distintas no campo organizacional da cultura ao longo do tempo, cada uma refletindo uma lógica histórico-social diferente.

Para a realização dessas fases foram coletados dados primários e secundários. Os dados secundários foram coletados mediante pesquisa bibliográfica em livros, documentos e periódicos que apresentassem descrições históricas do campo, bem como percepções críticas de seus autores quanto aos relacionamentos entre os atores do campo. Já os dados primários foram obtidos por meio de entrevistas.

Ao longo das entrevistas, foi seguido um roteiro construído a partir do modelo desenvolvido por Gomes (2005) para análise do setor elétrico brasileiro. A opção pelo uso desse modelo como apoio para a elaboração do roteiro de entrevistas se deu em virtude de o objetivo e o referencial teórico utilizados pelo autor se aproximarem bastante dos seguidos neste artigo. Além disso, o uso desse roteiro já demonstrou ser capaz de proporcionar depoimentos consistentes por parte dos entrevistados. Em razão das diferenças no objeto de pesquisa, o roteiro foi adaptado em relação à forma, no intuito de simplificar os termos utilizados e dinamizar o processo de entrevista; já em relação ao conteúdo, foram eliminadas algumas questões e acrescentadas outras que permitissem elucidar alguns pontos que necessitavam ser melhor explicitados.

A seleção dos sujeitos que formaram o grupo dos entrevistados para a pesquisa foi embasada em duas premissas: que o indivíduo respondente tivesse vivenciado duas configurações distintas do campo organizacional da cultura; e que a experiência e atuação do entrevistado no campo e na organização estivessem claramente comprovadas previamente pelo estudo do campo. Foram então realizadas entrevistas com oito especialistas da área da cultura no intuito de corroborar, corrigir e complementar os dados já encontrados, além de levantar novas questões diante do tema. As entrevistas tiveram, em média, duração de uma hora e meia e foram gravadas para posterior transcrição, com exceção da primeira, que tinha como objetivo inicial a validação e complementação do roteiro de entrevistas, além de dar um panorama geral do campo organizacional da cultura.

A escolha do número de entrevistados foi definida ao longo do processo, tendo em vista o volume, a qualidade e a repetição de dados coletados. De 
acordo com Gaskell (2002), se a avaliação do fenômeno é corroborada, é um sinal de que é tempo de encerrar as entrevistas, pois sua continuidade não melhora necessariamente a qualidade ou leva a uma compreensão mais detalhada do fato. Tendo em vista a saturação dos dados, foram entrevistados oito indivíduos ligados ao setor cultural, entre eles, pesquisadores, professores, gestores, curadores e artistas.

Quanto à análise dos dados, Gaskell (2002) aponta que não é um processo puramente mecânico; ele depende de intuições criativas. Assim, para o autor é fundamental a busca por contradições, pela maneira como as atitudes e opiniões se desenvolvem nas entrevistas, pelas clássicas racionalizações por parte do entrevistado. Buscou-se, ao longo da análise, apresentar uma interpretação dos dados bibliográficos e das entrevistas, tendo em vista o contexto em que foram realizadas, suas perspectivas ideológicas, área de atuação e momento histórico em que foram construídas. A perspectiva então adotada para análise dos dados bibliográficos e das entrevistas segue a análise de conteúdo que, conforme Dellagnelo e Silva (2005), é uma técnica extremamente útil para a os estudos organizacionais, por enfatizar a necessidade de sistematização de procedimentos e apoiar-se no estudo da linguagem. As autoras, a partir da classificação de Bardin (1977), estabelecem que o processo de análise é composto pelas seguintes etapas: (a) pré-análise, em que se busca fazer uma leitura geral do material, a fim de escolher e organizar o conteúdo a ser analisado; (b) exploração e análise do material, em que são realizadas a codificação e a categorização dos dados coletados; e (c) interpretação dos dados, realizada com base na teoria e na percepção do pesquisador. Um ponto importante na última etapa, segundo Dellagnelo e Silva (2005:113), "é a capacidade do pesquisador de questionar aquilo que vê imediatamente, as evidências, as ideias prontas", isto é, "sua capacidade de buscar novas interpretações".

\section{Evolução do setor cultural brasileiro}

A evolução do setor cultural brasileiro tem um enfoque organizacional, de forma a descrever com que dinâmica as organizações culturais foram se desenvolvendo no setor ao longo do tempo, tendo em vista o contexto social, político e econômico do qual fazem parte. A cultura brasileira ao mesmo tempo que importa elementos externos, cria e recria elementos novos que acabam dependentes entre si. Tal fato ilustra justamente a questão da contradição entre a dependência de uma cultura europeia ou americana em contraposição com a constante necessidade de reafirmação de uma cultura genuinamente 
nacional. Ou ainda, o fato de que diante de um contexto de mercantilização da cultura, manifestações tipicamente populares são reformuladas e adaptadas por grupos sociais muito diferentes.

Tal perspectiva pode ainda ser corroborada pelas ideias de Ianni (2004) de que a cultura cria-se e recria-se por meio da diversidade das relações sociais. A visão de Ianni (2004) sobre a cultura brasileira, em que antagonismos sociais manifestam-se por meio cultural pode ser comprovada ao observar-se que os conflitos presentes na sociedade em todos os momentos são de alguma forma reproduzidos ou tratados no campo. Crises políticas e econômicas, mudanças tecnológicas, novos padrões de relacionamento e de consumo, ideologias e interesses, uma vez presentes no ambiente de que a cultura faz parte acabam, em maior ou menor grau, influenciando a estruturação das configurações do campo.

Partindo-se da perspectiva de Ianni (2004), de que a cultura é construída e reconstruída socialmente, para iniciar uma descrição da trajetória do setor cultural no Brasil, é fundamental destacar a presença indígena, posteriormente à colonização portuguesa, e a presença negra. Tais fatos seriam as origens da cultura brasileira e, consequentemente, em conjunto com a vinda da missão francesa em 1816, as origens do campo organizacional da cultura no Brasil. A iniciativa da vinda da missão artística francesa dá-se por parte do Estado, com o objetivo inicial da criação de instituições na área da cultura. Percebe-se, assim, um interesse em civilizar os trópicos que provocou perdas significativas na cultura do país, conforme estes depoimentos:

com a missão artística francesa começa, vamos dizer assim, uma ação do Estado no sentido de criar instituições que no caso pudessem civilizar os trópicos.

(Entrevistada 2)

O grande perigo disso é e isso é quando a instituição interfere no sentido de colonizar essa cultura, no sentido de direcioná-la para seu interesse, (...) e a gente correu o risco e foi também danificado na perda de valores culturais importantes no Brasil, como por exemplo, o conhecimento indígena.

(Entrevistado 8)

Mais do que uma tentativa de civilização, conforme destaca a entrevistada 2, “...a missão francesa que, de certa forma, vai ser responsável pela modernização do campo da cultura" por parte do Estado. Talvez essa tenha sido uma primeira tentativa do Estado de intervenção, que contribuiu com a origem de uma primeira estruturação do campo da cultura. Após esse even- 
to, diversas manifestações foram acontecendo, evidentemente a maioria delas tendo como referência a cultura europeia. Até esse momento, os movimentos culturais e as organizações voltadas para a cultura são minimamente estruturados.

Porém, já no início da década de 1920, passa-se a questionar em que bases o país está sendo construído. Pode-se, a partir daí, destacar a industrialização e urbanização, uma movimentação da sociedade no repensar a cultura no Brasil, bem como o apoio por parte do Estado como os fatores que teriam promovido o surgimento da primeira configuração do campo organizacional da cultura: o campo da cultura como identidade. Já a segunda configuração do campo tem como bases o pensamento desenvolvimentista, o crescimento e o desenvolvimento de uma sociedade de consumo e o interesse do Estado no campo, constituindo então o campo da cultura como ideologia. A terceira configuração, por sua vez, surge de um momento de repressão e quebra com os movimentos anteriores, e diante da ameaça à segurança nacional, de uma forte intervenção do Estado na área da cultura com a criação de diversas organizações. Surge então o campo da cultura como estratégia. Por fim, diante das transformações na sociedade, de redemocratização, mas também de um esgotamento financeiro e da consolidação de um mercado, surge então a última configuração: o campo da cultura como mercado. Tal evolução das configurações é apresentada na figura a seguir.

\section{A história do campo organizacional da cultura no Brasil}

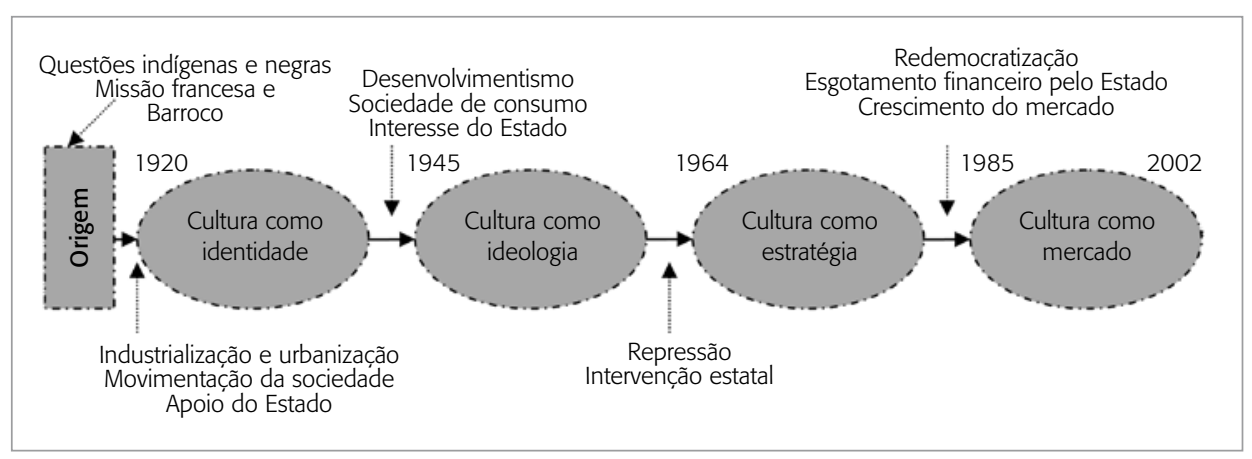

Fonte: Simões (2006).

As diferentes configurações do campo organizacional da cultura evidenciam o argumento de Scott (1994) de que um campo organizacional constituise de uma rede complexa de atores que mantêm relações de dependência, que compartilham valores e que estão definidos pelos mesmos processos simbóli- 
cos e regulatórios. A existência de distintas configurações e as mudanças na lógica que orienta a busca pela legitimidade em cada representação do campo, em conjunto com a diversidade de atores e de suas relações, demonstram a complexidade da estruturação da área da cultura no Brasil.

As transformações ocorridas no campo, resultantes de mudanças na lógica histórico-social que orientava as ações, que resultaram em quatro configurações distintas do campo, correspondem às mudanças nos órgãos estatais responsáveis pela cultura. Na primeira configuração e cultura como identidade, a responsabilidade para com a cultura caberia ao Ministério de Educação e Saúde Pública. Na segunda configuração, de cultura como ideologia, surgiria o Ministério da Educação e Cultura. Já na terceira configuração, de cultura como estratégia, foi lançada a Política Nacional de Cultura. Por fim, na última configuração, de cultura como mercado, foi então criado o Ministério da Cultura. Assim, cada campo possui suas especificidades e características, conforme o quadro.

\section{Caracterização das quatro configurações organizacionais do campo da cultura}

\begin{tabular}{|c|c|}
\hline $\mathrm{de}$ & \\
\hline $\begin{array}{l}\text { Fatores determinantes do campo - início da } \\
\text { industrialização e crescimento das cidades, } \\
\text { movimentação cultural por parte da sociedade, } \\
\text { criação de aparato administrativo e legal por } \\
\text { parte do estado } \\
\text { v Localização geopolítica do campo - centralizada } \\
\text { nos estados de RJ, SP e MG } \\
\text { V Grau de interação entre os atores - forte relação } \\
\text { de interesse entre Estado e intelectuais, influên- } \\
\text { cia direta dos intelectuais no Sphan, influência } \\
\text { do DIP na imprensa escrita } \\
\text { Vesenvolvimento de consciência mútua } \\
\text { - consciência mútua em torno da busca pela } \\
\text { consolidação de uma identidade nacional } \\
\text { v Estruturas de dominação - estruturas ainda } \\
\text { insipientes sendo criadas } \\
\text { vapel do Estado - apoiador e influenciador } \\
\text { Vapel do mercado - insipiente }\end{array}$ & $\begin{array}{l}\text { Fatores determinantes do campo - ideologia desen- } \\
\text { volvimentista, inovaçães tecnológicas e conflitos } \\
\text { políticos e sociais } \\
\text { v Localização geopolítica do campo - abertura para } \\
\text { novos estados além de SP, RJ e MG, como RS, BA } \\
\text { - Grau de interação entre os atores - relação forte, } \\
\text { conflituosa entre o Estado e a imprensa, dependência } \\
\text { financeira dos atores em relação ao Estado, depen- } \\
\text { dência financeira da imprensa, do teatro, do cinema } \\
\text { e da TV em relação ao mercado } \\
\text { vesenvolvimento de consciência mútua - manipula- } \\
\text { ção por parte do Estado para o desenvolvimento de } \\
\text { uma consciência mútua de desenvolvimentismo } \\
\text { - Estruturas de dominação - estruturas de dominação } \\
\text { estatais já estabelecidas, mas ainda não utilizadas em } \\
\text { sua plenitude, estruturas de dominação mercadoló- } \\
\text { gicas já em desenvolvimento } \\
\text { - Papel do Estado - manipulador e financiador } \\
\text { - Papel do mercado - em ascensão como } \\
\text { financiador }\end{array}$ \\
\hline
\end{tabular}




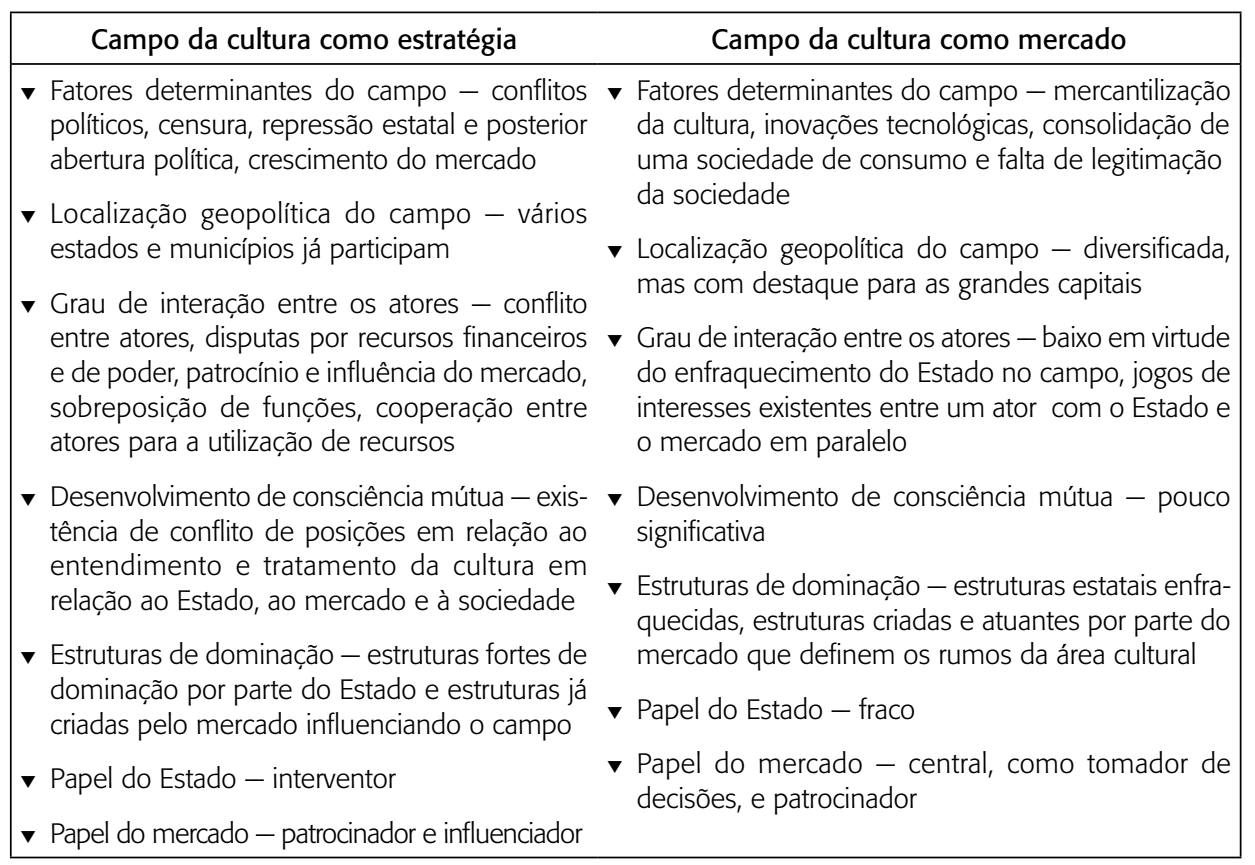

Fonte: Simões (2006).

Ao analisar cada uma das configurações percebe-se a existência de lógicas histórico-sociais distintas no campo, pois em cada momento a dinâmica de ações empreendidas pelos atores organizacionais corresponde a momentos de orientação para a formação de uma identidade nacional, de estabelecimento de uma ideologia no país, de defesa estratégica e de mercantilização da cultura. Além disso, em cada momento no campo é possível verificar um papel distinto tanto do mercado quanto do Estado.

\section{A influência do Estado e do mercado no campo organizacional da cultura}

A questão de que a mudança na lógica predominante no contexto histórico social definiria as transformações nas configurações do campo organizacional da cultura corresponde às ideias de Ianni (2004), segundo as quais a cultura e os atores a ela ligados vão se alterando conforme o contexto situacional. Nesse sentido, a cultura não poderia ser considerada algo coeso e homogêneo, e sim 
um campo complexo que é capaz de responder a diferentes lógicas predominantes na sociedade em cada momento.

Mas um ponto importante a ser ressaltado é que as quatro configurações organizacionais do campo da cultura representam momentos de maior ou menor institucionalização. Assim, é fundamental refletir a respeito da importância de saber o que confere legitimidade a certos arranjos institucionais. No caso brasileiro, parece que a lógica que orienta cada uma das configurações do campo da cultura define diretamente o seu grau de institucionalização. Isso porque quanto mais as ações dos atores vão ao encontro da lógica predominante no contexto histórico-social de cada período, maior legitimidade os atores obtêm e mais institucionalizado é o campo. Logo, quanto mais os atores respondem a uma lógica que não corresponde ao contexto brasileiro, como o caso da configuração da cultura como mercado, mais o campo sofre um processo de desinstitucionalização. Especificamente nesse caso, o processo não pode ser entendido no sentido defendido por Fonseca (2003) segundo o qual a desinstitucionalização estaria diretamente ligada ao fato de os atores deixarem de responder a questões impostas pelo ambiente externo. Isso porque essa desinstitucionalização, no caso do campo da cultura como mercado, seria justificada pelo fato de que a lógica mercadológica que orientava o campo não facilitaria um comportamento isomórfico por parte dos atores, nem sua legitimação perante o ambiente ao qual fazia parte, tornando assim o campo mais vulnerável à instabilidade.

A desarmonia entre eficiência e legitimidade, destacada por Goulart, Menezes e Gonçalves (2003), parece ser uma das razões pelas quais as criações, extinções e recriações de órgãos governamentais demonstram a incapacidade de construção e implementação de políticas públicas culturais continuadas e efetivas. As ações estatais empreendidas em resposta às pressões do ambiente poucas vezes tiveram um aparato administrativo e profissional capaz de executá-las de forma satisfatória.

$\mathrm{Na}$ análise das diferentes configurações do campo organizacional da cultura é possível verificar as categorias profissionais e o Estado como os principais atores institucionais no campo, comprovando a compatibilidade do argumento de DiMaggio e Powell (1991) com a realidade brasileira. Em todas as configurações do campo no Brasil, o papel do Estado é significativo, em maior ou menor grau, na estruturação do campo, bem como o papel dos profissionais, representados no campo pela classe artística, pelos arquitetos e pelos produtores culturais. Tais atores são centrais para o entendimento de cada configuração. 
O papel do Estado na dinâmica de estruturação do campo organizacional da cultura no país parece ir ao encontro do argumento defendido por Durand (2001), de acordo com o qual o Estado teria que atuar em relação à cultura em um espaço internamente dividido em subespaços que seguem lógicas diferentes. Em diversos momentos no tempo, cabia ao Estado agir diante de complexas diferenças regionais e diante de diversas concepções de cultura, como a cultura erudita, cultura popular e até mesmo diante de uma indústria cultural.

A análise a respeito do papel do Estado ao longo das distintas configurações do campo da cultura no Brasil parece, de certa maneira, enfraquecer o argumento de Scott (1995) de que o Estado atuaria em um campo organizacional como um agente coletivo que operaria basicamente por processos normativos e regulatórios. Apesar disso, neste artigo foram observados os múltiplos papéis desempenhados pelo Estado no campo. Parece que a teoria institucional, tendo em vista o contexto no qual foi originada, não permitiria uma análise mais completa a respeito da ação do Estado em um campo organizacional como o da cultura no Brasil.

O Estado, ao longo do tempo, tanto se ausentou das questões do campo como atuou por meio de suas organizações, de seus representantes e de sua influência sobre outros atores, de forma a direcionar, patrocinar, intervir, manipular, criar e definir a cultura no Brasil. Nesse sentido agiu, mesmo que com ações descontinuadas e pontuais, segundo seu interesse em cada momento. Mesmo na última configuração do campo, diante da predominância do mercado, seu papel ainda não pode ser considerado, do modo destacado por Scott (1995), como regulatório, diante de suas práticas descontinuadas, pouco diversificadas e passivas para o desenvolvimento da área cultural.

Em relação às categorias profissionais que atuaram no campo ao longo do tempo, parece que o argumento de Scott (1995) consegue explicar de forma mais consistente a realidade brasileira. As categorias profissionais presentes na trajetória do campo da cultura, como produtores culturais, artistas e arquitetos, sempre foram centrais para a evolução do campo. Os profissionais vindos da classe artística parecem ter desempenhado suas ações por meio de controles cognitivos e sistemas de crenças. Já os arquitetos e os produtores culturais foram, no campo da cultura, exemplos de atores que exerciam um papel normativo, criando tipificações e elaborando princípios de conduta e ação que definiriam muitas vezes a dinâmica de algumas relações no campo.

A ação estatal no campo da cultura como mercado parece corroborar o ponto de vista de Dória (2001), em que o Estado teria se posicionado definindo novos vínculos com a produção e com o consumo cultural. Tal argumento é verificado pelo fato de que nessa configuração o Estado criou leis que permi- 
tiram e impulsionaram a consolidação do papel central do mercado na cultura do país. Nesse sentido, talvez o argumento de Dória (2001) de que o Estado teria "inventado" o mercado no campo da cultura seja um pouco radical, mas não totalmente incorreto. Porque a predominância de uma lógica mercadológica no campo não seria exclusivamente responsável pela passividade estatal na cultura. O próprio desinteresse do Estado nas questões culturais como fatores estratégicos para o desenvolvimento do país, em conjunto com as dificuldades financeiras que o assolaram por muito tempo, justificaram o surgimento das leis de incentivo que deslocariam de vez a capacidade de decisão e gestão da cultura para o mercado.

A respeito do papel dos atores no campo, o ponto de vista de Vieira e Leão Júnior (2000), no qual a interação entre os atores seria fundamental para a dinâmica do campo, é verificado também nas distintas configurações do campo da cultura. Isso porque o volume e a intensidade das relações entre os atores que compõem o campo da cultura vão evidenciar também o grau de institucionalização de cada campo ao longo do tempo e também auxiliam o estabelecimento dos limites do campo.

Outro ponto que merece destaque na análise comparativa do campo é o fato de este estar centrado no Estado ou no mercado e os conflitos oriundos disso. Os depoimentos a seguir apontam algumas visões que evidenciam esse conflito.

No Brasil o campo da cultura sempre vai ser conflitante, porque ora está atrelado às questões do Estado, ora está atrelado às questões do mercado, como é o nosso caso atualmente.

(Entrevistada 2)

Eu não sou contra a mercantilização não, porque, afinal, a gente vive num sistema de mercado, e como é que o artista vai sobreviver? Então, eu acho que tem que, realmente, mercantilizar. Agora, o Estado pode entrar como um elemento regulador disso.

(Entrevistado 8)

Nos depoimentos dois pontos são centrais para as discussões do papel do Estado e do mercado no campo. O primeiro diz respeito ao fato dos limites da ação do Estado, que parecem ter, ao longo do tempo, ou assumido uma postura de intervenção e direcionamento para determinados interesses ou tendo um papel de omissão diante do campo. Outro ponto trata da questão da sobrevivência das organizações em uma dinâmica de mercado. 
Foi possível ainda comprovar em parte o argumento de Carvalho, Pacheco e Guimarães (2004) a respeito do papel do Estado e de suas políticas como determinantes das mudanças ocorridas nas ações dos atores no campo. Porque o Estado, em momentos distintos, atuou junto a eles de forma manipuladora, coercitiva e normativa, direcionando suas ações ou se apropriando de algumas de suas características. Porém, parece ser discutível o fato levantado por Carvalho, Pacheco e Guimarães (2004) de que o Estado estaria fomentando uma autossustentação das organizações culturais. Pelo contrário, nas três primeiras configurações ficou clara a dependência dos atores do campo em relação aos recursos e órgãos do Estado; já na configuração do campo da cultura como mercado, essa dependência passa a ser com o mercado, o que torna a situação preocupante, uma vez que muitas organizações, que não atendem aos interesses dele, já não têm mais condições de sobrevivência.

Evidentemente, a presença do mercado sempre existiu no campo. Entretanto, é importante destacar que em configurações anteriores parecia haver uma adaptação da cultura à condição de mercadoria, enquanto na última configuração, com a supremacia do mercado no campo, parece estar ocorrendo o processo inverso: a transformação de mercadorias em cultura, conforme os seguintes depoimentos.

Não, o mercado sempre atuou, nas estratégias de mercado você já encontra ressonância, desde o pop dos anos 1960 (...) o que acontece hoje é que há um esgotamento.

(Entrevistado 3)

Cultura, hoje, passa a ser o conceito de cultura que é dado por uma classe mais expressiva economicamente, (...) aí que o mercado tem um fator muito forte de mutação (...) ele pode transformar o conceito de cultura para aquilo que lhe é mais adequado.

(Entrevistada 2)

Com a evolução do mercado e crescente ausência do Estado essa compreensão foi deixada em segundo plano. Assim, o resgate da centralidade do papel do Estado na cultura é vital, como apontam os próximos depoimentos.

A base do governo é cultural, o governo em si é cultural, por isso é obvio que o papel é do Estado.

(Entrevistado 3)

Agora eu acho que ele (Estado) tem que interceder, de que maneira? Não é criando um modelo de cultura para o país não, quem cria um modelo de cultu- 
ra é a sociedade (...) deve é fomentar qualquer manifestação (...) pode servir como renovador desses fluxos de consumo e melhorar a qualidade intelectual de uma sociedade massificada.

(Entrevistado 8)

O Estado tem um papel absolutamente fundamental. É uma indecência o Estado não participar da cultura. Porque através da cultura você pode fazer com que as pessoas reflitam sobre elas mesmas, e tomem decisões mais de acordo com seus valores.

(Entrevistada 7)

Essa discussão tem dois entraves fundamentais no Brasil. O primeiro é exatamente a compreensão de quem faz parte da sociedade brasileira, da dificuldade de assumir e lidar com a existência de uma boa porção da população excluída dos processos políticos e sociais. Já o segundo, trata da dificuldade por parte do Estado em desenvolver políticas públicas de longo prazo na área da cultura que tenham um objetivo que corresponda ao contexto brasileiro. Outro ponto é que há uma dificuldade visível ao longo do tempo da adoção de uma perspectiva de continuidade e de efetividade das políticas públicas para a sociedade como um todo. Talvez o grande entrave para a construção de uma política cultural com essa visão esteja justamente ligada à difícil relação entre cultura e desigualdade, conforme evidenciam os seguintes depoimentos.

Quando você fala em diversidade cultural, você, de certa forma, esclarece, coloca em evidência uma desigualdade social e econômica.

(Entrevistada 2)

Quando você coloca a cultura como um selo a que você acrescentasse a formação do indivíduo, você continua no mesmo programa elitista.

(Entrevistada 2)

O papel do Estado também poderia ser o de garantir a democracia do campo, a oportunidade para todos.

(Entrevistado 8)

Mesmo assim, diante das dificuldades da criação de uma cultura homogênea no Brasil, parece que o enfoque dado às discussões a respeito das desigualdades sociais e também culturais não tem o mesmo destaque dado às relações de consumo dos chamados "produtos culturais". A partir dessa abordagem podem surgir duas suposições. A primeira consiste no fato de que a reprodução da perspectiva de cultura como mercadoria teria a capacidade 
de impor uma cultura homogênea, ao menos àquelas regiões ou classes sociais em que já existe uma sociedade de consumo consolidada. E a segunda, de que poderia estar sendo utilizado um discurso ilusório de diversidade cultural no intuito de mascarar a definição por parte do mercado — por meio da apropriação e transformação de determinadas manifestações culturais em produtos - do que seria a cultura brasileira.

Ao longo da evolução do campo organizacional da cultura é possível compreender como foi construída no país uma hierarquização cultural. As questões populares que inicialmente serviram de inspiração para a construção de uma identidade nacional por uma elite intelectual não abriram caminho para a valorização da cultura do povo, nem possibilitaram a abertura de espaços de participação para a população como um todo. Pelo contrário, com o passar do tempo, parece ter se solidificado uma grande distância entre as manifestações tipicamente originadas da realidade popular e a cultura oficial do Brasil. Aquela cultura definida ora pelas elites, ora pelo Estado, deveria ser entendida e consumida por toda a população.

Talvez no caso brasileiro a defesa dessa abordagem não seja declarada abertamente, já que muitas vezes ao longo da história do campo, parece ter sido defendida a ideia de uma cultura popular. Mas o que fica claro diante dos fatos e da prática dos atores é que essa cultura popular seria algo criado para o povo, e não pelo povo. Em alguns momentos ela teria sido minimamente tolerada ou ainda apropriada como fonte de inspiração ou produto. Diante de um discurso ilusório de igualdade social e aparente e desregulada parceria público-privada, o campo da cultura parece estar cada vez mais distante de um cenário para o desenvolvimento e cada vez mais próximo de uma realidade de cultura como negócio.

\section{Conclusão}

A respeito da influência do Estado e do mercado nas transformações ocorridas no campo organizacional da cultura no Brasil no período entre 1920 e 2002, pode-se afirmar, a partir da interpretação dos dados encontrados, que os atores interferiram na dinâmica do campo e no reflexo que as relações ocorridas neste tiveram perante a sociedade. Quanto mais intensa a presença do Estado no campo, maior a complexidade e maior o grau de institucionalização dele. Já em relação ao mercado, quanto mais presente este se faz no campo, mais os atores parecem ter dificuldades de se legitimar no ambiente, em razão da racionalidade do mercado pouco refletir o contexto brasileiro. Apesar disso, 
nem a ação do Estado nem a ação do mercado são suficientes para promover mudanças significativas na lógica que orienta a configuração organizacional do campo. As transformações nas configurações do campo organizacional da cultura acontecem somente quando a lógica determinada pela dinâmica histórico-social do ambiente ao qual o campo faz parte se modifica.

Assim, a lógica que orienta cada uma das configurações do campo da cultura define diretamente a forma como o campo está estruturado e seu grau de institucionalização. Isso porque quanto mais as ações dos atores vão ao encontro da lógica predominante no contexto histórico-social, maior a legitimidade desses atores e mais institucionalizado é o campo. Logo, quanto mais os atores respondem a uma lógica que não corresponde ao contexto brasileiro, mais o campo parece sofrer um processo de desinstitucionalização. A ocorrência de um processo de desinstitucionalização justifica-se pelo fato de que a lógica que orienta o campo não facilita um comportamento isomórfico por parte dos atores nem sua legitimação perante o ambiente ao qual fazia parte, tornando assim o campo mais vulnerável à instabilidade.

Além disso, os antagonismos sociais e os conflitos presentes na sociedade brasileira em todos os momentos são, de alguma forma, reproduzidos ou tratados no campo. Crises políticas e econômicas, efeitos de mudanças tecnológicas, novos padrões de relacionamento e de consumo, ideologias e interesses acabam, em maior ou menor grau, influenciando a estruturação do campo.

Outra característica do campo diz respeito à desarmonia entre eficiência e legitimidade, que parece ter dificultado uma estruturação consistente do campo e uma ação estatal efetiva. Isso porque as ações do Estado, empreendidas em resposta às pressões do ambiente, poucas vezes tiveram um aparato administrativo e profissional capaz de executá-las de forma satisfatória.

$\mathrm{Na}$ análise das diferentes configurações do campo organizacional da cultura é possível verificar ainda as categorias profissionais - intelectuais e produtores culturais - e o Estado como os principais atores estruturadores do campo. O Estado ao longo do tempo tanto se ausentou das questões do campo como atuou por meio de suas organizações de forma a direcionar, patrocinar, intervir, manipular, criar e definir a cultura no Brasil. Suas ações foram, em geral, descontinuadas e pontuais, segundo seu interesse em cada momento. Mesmo diante de uma consolidação por parte do mercado, o Estado parece ter tido dificuldades ou desinteresse em desempenhar um papel de regulador da área cultural. Já quanto às categorias profissionais, os intelectuais vindos da classe artística parecem ter desempenhado suas ações via controles cognitivos e sistemas de crenças, enquanto os arquitetos e os produtores culturais exerceram um papel de natureza normativa. 
A consolidação da orientação mercadológica no campo foi em grande parte promovida pela própria ação ou inércia do Estado no campo. A criação de leis de incentivo e o desinteresse estratégico do Estado nas questões culturais, em conjunto com as dificuldades financeiras que assolaram o país por muito tempo, deslocaram de vez a capacidade de decisão e gestão da cultura para o mercado.

Um ponto que merece destaque diz respeito à utilização da teoria institucional na análise da cultura no Brasil. Embora a abordagem tenha sido suficiente para construir um quadro comparativo do campo da cultura, sua capacidade explicativa fica limitada quanto ao entendimento do papel do Estado, bem como dos fatores promotores da mudança na configuração do campo e dos processos de desinstitucionalização. Além disso, a teoria não parece apresentar um arcabouço crítico capaz de compreender suficientemente as consequências da mercantilização da cultura no Brasil.

A compreensão do papel do Estado apenas como regular não corresponde às ações empreendidas por ele no caso brasileiro, uma vez que com o Estado parece ter se apropriado da cultura como ferramenta de manipulação e sustentação política, além de ter agido de forma coercitiva. Quando deveria agir como regulador, sua ação foi inconsistente. Além disso, os dados permitiram inferir que o Estado foi o principal responsável pela criação do "povo da cultura" em oposição à "cultura do povo". Além disso, ao permitir, com o avanço do mercado e com a consolidação de uma indústria cultural, o significado da cultura estaria sendo remodelado, despotencializando a capacidade crítica dos indivíduos, promovendo a alienação e conformismo social e direcionando a administração da cultura para uma situação que separa quem produz de quem consome.

Nesse sentido, o resgate da centralidade do papel do Estado na cultura é fundamental. Para isso, é necessário buscar-se uma compreensão da cultura no contexto brasileiro, marcado por desigualdades sociais, pela hierarquização da cultura construída ao longo do tempo e pela já consistente indústria cultural.

\section{Referências}

CARVALHO, Cristina; VIEIRA, Marcelo Milano Falcão; LOPES, Fernando. Contribuições da perspectiva institucional para a análise das organizações. In: ENCONTRO ANUAL DA ASSOCIAÇÃO NACIONAL DE PÓS-GRADUAÇÃO EM ADMINISTRAÇÃO, 25. Anais... Foz do Iguaçu: Anpad, 1999. 
DELLAGNELLO, Eloise; SILVA, Rosimeri Carvalho. Análise de conteúdo e sua aplicação em pesquisa em administração. Pesquisa qualitativa em administração: teoria e prática. Rio de Janeiro: FGV, 2005.

DIMAGGIO, Paul; POWELL, Walter. The iron Cage revisited: institutional isomorphism and collective rationality in organizational fields. The new institutionalism in organizational analysis. London: University of Chicago Press, 1991.

DURAND, José Carlos. Cultura como objeto de políticas públicas. São Paulo Perspectiva, v. 15, n. 2, São Paulo, abr./jun., 2001.

GASKELL, George. Entrevistas individuais e grupais. In: ; BAUER, Martin (Orgs.). Pesquisa qualitativa com texto, imagem e som. 3. ed. Petrópolis: Vozes, 2002.

GOMES, João. O campo da energia elétrica no Brasil. 2005. Dissertação (Mestrado) - Escola Brasileira de Administração Pública e de Empresas, Fundação Getulio Vargas, Rio de Janeiro, 2005.

GOULART, Sueli; VIEIRA, Marcelo M. F. Desenvolvimento, poder local e estrutura simbólico-normativa das universidades. In: CARVALHO, Cristina; VIEIRA, Marcelo M. F. Organizações, cultura e desenvolvimento local: a agenda de pesquisa do observatório da realidade organizacional. Recife: Edufepe, 2003.

IANNI, Octávio. A ideia de Brasil moderno. São Paulo: Brasiliense, 2004.

LEÃO JR., Fernando Pontual de Souza; VIEIRA, Marcelo. Jogos de poder: institucionalização e mudança no Museu de Arte Moderna do Recife. In: ENCONTRO ANUAL DA ASSOCIAÇÃO NACIONAL DOS PROGRAMAS DE PÓS-GRADUAÇÃO EM ADMINISTRAÇÃO, 24., 2000, Florianópolis. Anais... Rio de Janeiro: Anpad, 2000. 1 CD-ROM.

MACHADO-DA-SILVA, Clóvis; FONSECA, Valéria; FERNANDES, Bruno. Cognição e institucionalização na dinâmica das mudanças em organizações. In: RODRIGUES, Suzana B.; CUNHA, Miguel P. (Orgs.). Estudos organizacionais: novas perspectivas na administração de empresas. São Paulo: Iglu, 2000.

MARQUES, Fernando Pereira. De que falamos quando falamos de cultura. Lisboa: Presença, 1995.

MENEZES, Michelle F.; GONÇALVES, Júlio César; GOULART, Sueli. Composição e características do campo organizacional dos museus e teatros da região metropolitana de Recife. In: CARVALHO, Cristina; VIEIRA, Marcelo M. F. Organizações, cultura e desenvolvimento local: a agenda de pesquisa do observatório da realidade organizacional. Recife: Edufepe, 2003. 
MEYER, John W.; ROWAN, Brian. Institutionalized organizations: formal structure as myth and ceremony. In: The new institutionalism in organizational analysis. London: University of Chicago Press, 1991.

PACHECO, Flávia Lopes; GUIMARÃES, Rodrigo Gameiro; CARVALHO, Cristina. Análises Organizacionais no Campo da Cultura e a Importância do Estado. In: ENCONTRO DE ADMINISTRAÇÃO PÚBLICA E GOVERNANÇA, 1., 2004. Anais... Rio de Janeiro: Anpad, 2004. 1 CD-ROM.

SCOTT, Richard. Introduction: institutional theory and organizations. In:

CHRISTENSEN, Soren. The institutional construction of organizations: international and longitudinal studies. Thousand Oaks (CA): Sage Publications, 1995.

SIMÕES, Janaina Machado. O campo da cultura no Brasil: entre o Estado e o mercado. 2006. Dissertação (Mestrado) — FGV, Rio de Janeiro, 2006.

VIEIRA, Marcelo. Por uma boa pesquisa (qualitativa) em administração. In:

ZOUAIN, Débora M. (Orgs.). Pesquisa qualitativa em administração. Rio de Janeiro: FGV, 2004.

; CARVALHO, Cristina Amélia. Campos organizacionais: de wallpaper a construção histórica do contexto de organizações culturais em Porto Alegre e em Recife. In: ENCONTRO ANUAL DA ASSOCIAÇÃO NACIONAL DOS PROGRAMAS DE PÓS-GRADUAÇÃO EM ADMINISTRAÇÃO, 27., 2003, Atibaia. Anais... Rio de Janeiro: Anpad, 2003a. 1 CD-ROM.

; . Contribuições da perspectiva institucional para a análise das organizações: possibilidades teóricas, empíricas e de aplicação. In: Organizações, cultura e desenvolvimento local: a agenda de pesquisa do observatório da realidade organizacional. Recife: Edufepe, 2003b.

. ; SILVA, Rosimeri Carvalho. The process of historic evolution of organizational fields: an analysis of museums and theatres in Southern and Northeastern Brazil. International Journal of Arts Management, v. 11, n. 2, Montreal, Winter 2009. 